\title{
PREVENÇÃO AO CRIME E TEORIA SOCIAL
}

João Trajano Sento-Sé

A perspectiva da prevenção ao crime ganhou tamanho destaque a partir do último quarto do século passado que pode ser, hoje, encarada como uma espécie de subárea do campo da criminologia. O interesse relativamente tardio por essa linha de análise costuma ser explicado em função do predomínio do positivismo como marco teórico da criminologia desde a segunda metade do século XIX. De acordo com essa linha de argumentação, o deslocamento da centralidade do indivíduo como referência de análise, típica do positivismo, para a ênfase nos fatores sociais e ecológicos que concorrem à incidência de crimes seria um fator determinante para a consolidação da abordagem preventiva.

Aceitando-se tal perspectiva, assume-se, basicamente, um distanciamento radical entre as bases ontológicas e os postulados teóricos que orientam a criminologia positivista e a criminologia sociológica. Tal distância teria como um de seus desdobramentos o desenvolvimento tardio de esforços de compreensão do fenômeno criminal com vistas à produção de um saber aplicado voltado para sua prevenção. 
Embora pertinente à primeira vista, julgamos que tal forma de diferenciar essas duas grandes correntes é equivocada. Em primeiro lugar, a perspectiva preventiva, no campo teórico, ao menos esteve presente, inclusive em sua acepção situacional, com bastante destaque, entre os mais influentes representantes da criminologia positivista. Em segundo lugar, embora teoricamente a figura do indivíduo seja tomada de formas bastante diferenciadas, ela ocupa um lugar tão importante nas diferentes correntes sociológicas quanto podemos observar nas formulações positivistas.

É verdade que as formas de apropriação e a operacionalização analítica são bastante distintas. Tal distinção é ainda mais acentuada no que tange aos procedimentos metodológicos. Há um abismo entre os preceitos biológicos dos positivistas e as formulações fundadas em bases sociológicas. Nada é mais estranho ao criminólogo de inspiração sociológica do que o uso das técnicas antropométricas da criminologia positivista. Definição de traços fisionômicos e medição de estruturas cranianas e outros procedimentos científicos próprios ao positivismo costumam ser lembradas, hoje, como marcas quase patéticas de procedimentos que mereceriam o escárnio se sobre eles não se sobrepusesse o repúdio pelos componentes discriminatórios de natureza regional ou étnica que traziam embutidos ou acabaram por legitimar. Diante disso, fica em segundo plano a obsessão pelas regularidades e a expectativa de se estabelecer cálculos probabilísticos que atravessam a criminologia dos positivistas até os dias atuais.

As diferenças seguem nos modos de significação e apropriação do indivíduo como referência de análise. A criminologia positivista partia da análise da constituição física e psicossomática do indivíduo para, decodificando seus traços, inseri-lo em uma das categorias das tipologias arduamente estabelecidas. As diferentes perspectivas sociológicas buscam nas condições e trajetórias sociais os indícios de car- 
reiras mais propensas ao envolvimento recorrente em episódios criminais. Diante do já consagrado reconhecimento dessas distâncias, talvez seja produtivo reconhecer: o indivíduo está sempre ali, analiticamente relevante e idiossincrático, assim como o seu ajuntamento abstrato, pelo efeito de perguntas que se consagram e se repetem; compõe grupos de risco, personalidades típicas e fatores de risco. Uma vez decodificados, temos, por caminhos que se tangenciam, a recolocação de problemas que podem ser encarados como menor pendor ao ineditismo: alcoolemia, prostituição, ambientes fraturados etc.

Em ambos os casos, portanto, a decodificação dos elementos individuais acaba ocupando posição central analiticamente e, por conseguinte, pautando preceitos prescritivos. Também é coincidente a admissão das tensões teóricas e práticas que perpassam a abordagem entre a ordem coletiva e o particularismo individual, bem como a incidência da primeira sobre o segundo.

Finalmente, cabe destacar que embora o distanciamento que temos da escola positivista nos permita divisar com alguma clareza algumas de suas fragilidades e desdobramentos discriminatórios de sua doutrina, não dispomos do mesmo benefício, quando se trata de precisar precariedades equivalentes nas correntes contemporâneas. Quanto a esse último ponto, talvez seja de alguma valia o exercício de aproximação entre ambas as correntes. Ao colocá-las em diálogo, talvez consigamos não somente tornar mais familiares preceitos, dificuldades, fragilidades e eventuais virtudes da corrente positivista, que, em geral tende a gozar de pouco apreço por parte dos sociólogos, como, principalmente, assumir alguma distância do que nos é familiar, ao aproximá-lo daquilo de que nos julgamos já tão distanciados.

Tendo em vista o que foi posto nas últimas linhas do parágrafo anterior, o objetivo deste artigo é explorar algumas continuidades e deslocamentos que perpassam a passa- 
gem da criminologia positivista para algumas das correntes contemporâneas da genericamente chamada criminologia sociológica. Tal exploração se dará a partir da discussão da prevenção à violência. Há algumas razões para tal escolha que merecem ser destacadas.

Ao tomar o problema da prevenção, resgatamos um aspecto pouco explorado da chamada criminologia positivista e, como mencionado na abertura, bastante importante na literatura atual. Em segundo lugar, a perspectiva preventiva explicita uma característica que perpassa toda a história de constituição da criminologia moderna: seu caráter de ciência eminentemente aplicada. Por fim, assumindo tal chave analítica, podemos efetuar mais claramente a ligação entre uma discussão teórica e suas implicações no mundo da vida.

$* * *$

A expectativa antecipatória embutida no esforço para a decodificação dos fatores que concorrem para a prática de condutas antissociais enquadradas juridicamente como criminosas está presente mesmo antes da criminologia ser entendida como campo específico de conhecimento. Ela é uma das melhores expressões do "construtivismo" teórico de que fala Hayek (1978) como marca do saber de inspiração iluminista. A ambição de definir todos os fatores relevantes e suas combinações que resultam nos fenômenos sociais levaria o homem moderno a supor possível, através de intervenções cientificamente orientadas, interferir sobre os rumos da sociedade, produzindo artificialmente os arranjos desejáveis para a promoção de uma vida mais harmoniosa. Ambição ilusória, segundo Hayek, ela é marca de origem a qual se perpetua no campo da criminologia, sobretudo no que ela se volta à prevenção.

Já na chamada criminologia clássica, a perspectiva preventiva aparece em diversas passagens na principal obra de 
Beccaria, mais conhecido, citado e criticado teórico da criminologia tal como formulada em termos modernos.

Não só é interesse comum que não sejam cometidos delitos, mas também que eles sejam tanto mais raros quanto maior o mal que causam à sociedade. Portanto, devem ser mais fortes os obstáculos que afastam os homens dos delitos na medida em que estes são contrários ao bem comum e na medida dos impulsos que os levam a delinquir. Deve haver, pois, uma proporção entre os delitos e as penas (Beccaria, 2005, p. 50).

A adequada proporção entre delitos e penas não é somente uma preocupação que inscreve o pensamento de Beccaria no espírito reformador do iluminismo. Ela torna eficaz a punição naquilo que ela tem de mais relevante: impor limites a difusão de condutas criminais evidenciando ao corpo social em geral e a seus membros em particular a justa medida guardada entre delito e punição. O caráter dissuasório da pena sobrepõe-se a seu componente retributivo.

Das simples considerações das verdades até aqui expostas, resulta evidente que o fim das penas não é atormentar e afligir um ser sensível, nem desfazer um delito já cometido [...]. O fim, pois, é apenas impedir que o réu cause novos danos aos seus concidadãos e dissuadir os outros a fazer o mesmo.

É, pois, necessário escolher penas e modos de infligi-las, que, guardadas as proporções, causem a impressão mais eficaz e duradoura nos espíritos dos homens, e a menos penosa no corpo do réu (Beccaria, 2005, p. 62).

Embora à primeira vista o objeto da punição seja o violador da lei, na doutrina formulada por Beccaria este é um 
personagem secundário em relação àquilo que efetivamente deve ser o foco da punição: em primeiro lugar, o delito em si, do qual o perpetrador é pouco mais do que uma perturbadora atualização empírica; em segundo lugar, mas de modo algum subsidiariamente, todos os demais membros do corpo social, infratores potenciais ou não, a quem se dirige a sentença segundo a qual a ação indesejável será exemplar e justamente punida.

A ambição preventiva justifica-se doutrinariamente pela expectativa de fazer desse campo, o estudo das penas e de sua aplicação, um instrumento capaz de prover a sociedade de recursos de autoproteção, minimizando a incidência criminal e as práticas que, em tese, poriam a ordem social em xeque. Ainda que uma parcela da literatura dedicada ao estudo dos sistemas punitivos explicite o fracasso dessa ambição, o caráter dissuasório e suas inevitáveis implicações preventivas estiveram presentes nas origens do pensamento 14 criminológico moderno e atravessaram as diversas formulações a respeito do sistema punitivo até o século XX.

A criminologia positivista lança suas bases em grande medida se contrapondo teórica e metodologicamente à criminologia clássica, personificada em Beccaria. Da perspectiva de Lombroso, a criminologia clássica é insuficiente por negligenciar a análise empírica, restringindo-se a compor um corpo doutrinário abstrato e sem conexão com as dinâmicas reais do mundo social. Falta cientificidade à criminologia clássica porque falta investigação empírica. Falta efetividade em suas prescrições porque elas se resumem ao campo da jurisprudência como se ela, por si só, fosse capaz de decifrar as motivações para o crime e interferir sobre elas.

Referência principal da consolidação da criminologia como campo singular de conhecimento científico, Lombroso é desses autores em que o prestígio de duas ou três teses junto a seus contemporâneos acaba por se estender na história funcionando nos tempos futuros no sentido oposto. 
Muito do que lhe conferiu prestígio em seu tempo o projetou para uma espécie de maldição na história. Em ambos os tempos, o seu e o que lhe sucedeu, suas teses mais conhecidas acabaram ofuscando aspectos que pareciam a ele mesmo relevantes em sua própria doutrina.

A partir de um exaustivo trabalho de observação clínica nas instituições carcerárias e asilos, Lombroso dedicou-se a um incansável trabalho de construção de uma tipologia de indivíduos propensos a perpetração de atos criminosos. Ao longo das cinco edições de seu principal trabalho publicadas durante sua vida, ele retifica, revê e redefine os tipos criminais observados, atestando uma constante insatisfação com os resultados alcançados. Daí extraiu boa parte de seu prestígio em vida e da maldição posterior. Suas teses sobre os tipos naturalmente criminosos sobressaíram em relação às não menos importantes asserções sobre as personalidades tornadas "antissociais" em função de fatores sociais, culturais e econômicos. Do mesmo modo, suas não poucas análises sobre tais fatores e as formas de lidar com eles acabaram relegadas a segundo plano, ficando obscurecidas como parte menor de seu corpo teórico.

Um desses aspectos, obscurecido pelas teses atávicas e naturalistas pelas quais o clínico italiano ficou conhecido é exatamente aquele que enfeixa seu interesse nos mecanismos de prevenção à violência. Desde a primeira até a quinta edição de The criminal man ${ }^{1}$, Lombroso dedica espaço para orientações voltadas para a prevenção da violência. É assim que, na abertura de capítulo específico sobre o tema, na segunda edição (de 1878), ele sentencia:

Se nós aceitamos a realidade da reincidência, que prevalece em todos os sistemas penitenciários, nós temos

\footnotetext{
${ }^{1}$ Trabalhamos, aqui, com a edição inglesa, de 2006, sob a responsabilidade de Mary Gibson e Hahn Rafter, que reúne as cinco versões editadas por Lombroso de sua obra (Lombroso, 2006).
} 
que buscar um ponto de partida para novas terapias para lidar com o crime. Em lugar de tentar curar o crime, devemos tentar preveni-lo, neutralizando suas causas (Lombroso, 2006, p. 135).

A abordagem do sistema carcerário e o estudo das penas, que o coloca em lado oposto ao de Beccaria, é um exemplo da atenção dedicada à prevenção. Embora tenha alternado entre uma rejeição peremptória ao encarceramento e a sua aceitação como recurso aceitável para lidar-se com o crime, Lombroso manteve-se fiel à avaliação de que, ao contrário do que supunha a criminologia clássica, o encarceramento era absolutamente ineficaz como mecanismo preventivo. As desejáveis e imprescindíveis medidas de prevenção estariam em outro lugar e não se restringiriam de modo algum à esfera do sistema judiciário ou policial.

$\mathrm{O}$ argumento desenvolvido por Lombroso e a centralidade concedida a iniciativas de proteção a crianças revelam, por vezes, surpreendente proximidade às análises sobre fatores de risco, desenvolvidas contemporaneamente. Ao modelo dos reformatórios que se resumem a aprisionar os jovens em uma "atmosfera de vício concentrado”, Lombroso advoga a expansão de escolas e instituições industriais e cooperativas que desenvolvam "o respeito à propriedade, o amor ao trabalho e a sensibilidade para o belo" em indivíduos que, por não terem ainda o caráter formado, são vulneráveis às "más influências". (Lombroso, 2006, p. 138)

Na quinta edição de Criminal man (1896-1897), Lombroso retoma a questão da prevenção, desenvolvendo prescrições sobre algumas modalidades criminais - como os crimes sexuais e a fraude -, defendendo a adoção de métodos científicos no trabalho policial, criticando aspectos do sistema de justiça criminal e identificando fatores socioeconômicos que, a seu ver, concorreriam para o aumento da incidência 
criminal $^{2}$. Ao longo de sua trajetória, sem jamais abdicar do método que começava na investigação dos traços individuais do criminoso, cresce seu interesse pelas influências negativas exercidas sobre os criminosos habituais e latentes, os dois tipos que, a despeito de eventuais características inatas, tinham nas circunstâncias de seu entorno fatores decisivos para a explicação de seu comportamento.

A essa altura, Enrico Ferri, ex-aluno de Lombroso e tido por Garland (2002) como o "mais sociológico dos criminologistas positivistas", já publicara seu importante Criminal sociology, estudo em que, a um só tempo, procede a reparos a algumas das teorias do mestre e dá continuidade a sua obra.

Também empenhado em consolidar cientificamente um saber sobre os comportamentos antissociais em termos semelhantes àqueles que as ciências naturais alcançaram no estudo da natureza, Ferri avança nos estudos clínicos e na observação dos indivíduos capturados pelo sistema de justiça criminal. Daí espera extrair um corpo teórico próprio às ciências humanas:

Se a antropologia geral é, segundo a definição de M.

Quatrefagues, a história natural do homem, assim como a zoologia é a história natural dos animais, a antropologia criminal nada mais é do que o estudo de um tipo específico da espécie humana. Em outras palavras, ela é a história natural do homem criminoso (Ferri, 2009, p. 136).

Simultaneamente à construção de um argumento que remete a criminologia ao modelo das ciências naturais, Ferri advoga, para a consolidação desse saber, uma composição de três campos disciplinares - a antropologia, a psiquiatria

\footnotetext{
${ }^{2}$ Nesse último caso, cabe destacar a polêmica, mas instigante, tese segundo a qual não seria a pobreza, mas o aumento desmesurado da riqueza que concorreria para o aumento das incidências criminais (Lombroso, 2006, p. 334).
} 
e a sociologia. Somente mediante tal composição a criminologia efetivamente se consolidaria como corpo científico próprio para lidar com a questão do crime, superando o dogmatismo doutrinário e abstrato das abordagens puramente jurídicas da criminologia clássica. A consolidação de uma sociologia criminal apoiada no uso de métodos estatísticos ocupa, a rigor, mais que dois terços de sua obra mais elaborada e conferiria, para ele, solidez prática a esse novo campo do conhecimento.

É importante destacar que o indivíduo criminoso é para Ferri, assim como o era para Lombroso, a fonte privilegiada de informações sobre a etiologia do comportamento criminal. Os fatores que incidem para a configuração de personalidades propensas a esse tipo de comportamento, contudo, são bem mais amplas e estão longe de se restringirem a elementos inatos.

já que as origens naturais do crime surgem não somente do organismo individual, mas, também, em larga escala, do seu entorno físico e social, para a recuperação do indivíduo não é suficiente apenas prevenir a reincidência sem que se mobilize o melhor de nossos recursos para intervir também em seu entorno social (Ferri, 2009, p. 78).

Firmada tal combinação, a criminologia estaria, então, apta a cumprir seu papel social de fornecer os insumos capazes de proteger a sociedade da incidência exagerada de comportamentos desviantes, através da orientação de medidas preventivas.

Em sua obra como um todo, Ferri destina boa parte de seus esforços no aperfeiçoamento da tipificação do homem criminoso e, nessa perspectiva, enfatiza os aspectos atávicos e inatos que caracterizariam os perpetradores preferenciais de certas modalidades de crime. Por outro lado, ele destaca reiteradamente, em diversas passagens, a relevância das con- 
dições sociais e econômicas que concorrem para a formação de personalidades mais propensas a determinadas condutas criminais. Tais condições não seriam dadas, tampouco estariam enfeixadas, em condições biológicas ou naturais. Por essa razão, ao elencar algumas medidas para a redução da incidência criminal, Ferri parece antecipar alguns dos preceitos formulados, décadas depois, por diferentes correntes:

Existem crimes de pirataria nos dias de hoje, mas o uso de recursos náuticos mais velozes tem sido mais eficaz para evitá-los do que todos os códigos penais. Embora raros, homicídios continuam a ocorrer em autoestradas, mas não é menos verdadeiro que a substituição das antigas diligências e o uso de carruagens pelas autoestradas e ferrovias reduziu os assaltos nas estradas, com ou sem mortes. O divórcio não eliminou a ocorrência de casos de assassinatos de mulheres por seus maridos em função do adultério, mas reduziu sua incidência. Do mesmo modo, após a implantação de mecanismos de suporte e proteção a crianças abandonadas não estaremos aptos a fechar os tribunais, pela supressão de incidências criminais, mas elas certamente diminuirão consideravelmente (Ferri, 2009, p. 1563).

As intervenções apontadas aqui poderiam facilmente ser identificadas como parte dos programas prescritivos e das hipóteses que fundamentam algumas das abordagens recentes sobre formas de redução do crime. Elas patenteiam a expectativa não somente de fundação de um novo campo científico, mas de colocá-lo a serviço da sociedade como instrumento de construção de uma ordem num contexto de mudanças profundas. Compõem um protoprograma de prevenção que se bate contra as teses pautadas no endurecimento penal, não propriamente lançando mão de argumentos supostamente humanitários, mas relativos à eficiência e à efetividade. 
Em sua interlocução crítica com Beccaria, Lombroso insiste na necessidade de se conferir tratamento empírico ao fenômeno criminal como recurso necessário para conferir-lhe base científica. Na tentativa de levar adiante a tarefa do ex-professor, Ferri esmera-se em qualificar melhor a tipologia por ele criada, concedendo maior atenção a aspectos sociológicos que, ainda que pouco explorados, já estavam presentes em Lombroso. O mesmo espírito reformador, contudo, estava presente nos três e, de certa forma, constitui uma das marcas de origem da criminologia moderna.

Certamente, tanto Lombroso quanto Ferri são exemplares de um paradigma da análise criminal orientada pela construção de uma tipologia de comportamentos criminais em que o indivíduo e sua constituição se encontram em primeiro plano. Nessa chave, os aspectos inatos, constitutivos dos indivíduos, são, indiscutivelmente, o foco maior

20 de atenção e de estudo desses autores - que estão entre os principais de seu tempo, tanto quanto de seus pares e seguidores mais diretos. Trata-se de uma espécie de tributo que, vistas retrospectivamente, as obras de Lombroso e Ferri pagam a seu momento histórico.

Cabe notar, contudo, que o lugar do indivíduo é efetivamente central em virtude de seu lugar metodológico. Da observação do indivíduo, na decodificação de seus traços físicos, psíquicos e sociais, Ferri e, sobretudo, Lombroso, extraem os subsídios para a construção de suas respectivas tipologias. Pela estatística, Ferri pretende ampliar o rendimento de seus avanços em escala mais ampla, admitindo explicitamente seriam fatores sociais que incidiriam para a ampliação desmesurada da incidência de três dos cinco tipos por ele estabelecidos ${ }^{3}$.

\footnotetext{
${ }^{3}$ Segundo a tipologia de Ferri, existem cinco tipos criminosos: os loucos, criminosos natos, os criminosos decorrentes de hábitos adquiridos, os criminosos ocasionais e os criminosos passionais.
} 
Curiosamente, nesse aspecto em que os recursos metodológicos tidos por mais científicos são mobilizados - não somente as análises clínicas e antropométricas, mas, também, a estatística - suas pesquisas se revelam, hoje, mais frágeis e passíveis de apropriações estranhas a suas próprias intenções. Por outro lado, as enumeráveis intuições sociológicas, motivadas possivelmente pela aspiração aplicada de seus estudos, não decorrem diretamente de inferências "empíricas". Elas são, no melhor sentido da palavra, intuições, as quais dão atenção prudente, mas reiterada em suas intervenções teóricas. Tomando-as a sério, e destacando-as como resultados de um longo processo de amadurecimento, podemos colocá-las em diálogo com algumas abordagens recentes e, inversamente, identificar, ali onde hoje se estabelecem prescrições e inferências fundadas empiricamente, preceitos normativos não muito explícitos à primeira vista. Façamos esse salto a partir de algumas abordagens sobre a prevenção da violência sustentadas por perspectivas inspiradas no que, de forma geral, poderíamos chamar de criminologia sociológica. Podemos antecipar que, malgrado seu, o lugar do indivíduo nesses casos é maior do que seria suposto inicialmente, assim como os aspectos sociológicos foram surpreendidos nas bases da criminologia positivista.

$* * *$

Há, hoje, algumas formas de organizar e distinguir as diferentes modalidades de prevenção à violência. A mais geral delas, define essa prevenção segundo seu alcance e público alvo. Tal como estabelecido por Brantingham e Faust (1976), há três níveis de abordagens de prevenção: primária, secundária e terciária. A prevenção primária é concebida como uma abordagem abrangente, que articula ações a partir da identificação de áreas e públicos potencialmente sujeitos a serem arrastados pela violência, antes que 
ela instaure-se efetivamente. A prevenção secundária seria mais circunscrita. Ela diria respeito a populações e regiões identificadas como portadoras de características passíveis de serem identificadas como zonas de risco. Finalmente, a prevenção terciária diria respeito a iniciativas focadas em áreas conflagradas ou evidentemente identificadas como espaços recorrentes de episódios criminais e populações reconhecidas como vítimas ou agressores consumadas. Uma variante dessa primeira tipologia (Gärtner, 2008) descreve a prevenção primária como aquela focada na intervenção sobre as condições gerais, sejam físicas ou humanas, que favorecem a recorrência de episódios violentos; a secundária seria voltada para indivíduos ou grupos que, a partir de determinadas características, estariam mais vulneráveis ao envolvimento em situações de violência, seja na condição de autor, seja na de vítima; a terciária, orientada para a redução da recorrência criminal por pessoas já identifica22 das como perpetradoras de violência, teria a expectativa de evitar a reincidência.

Essa primeira tipologia peca por sua generalização, mas, levando-se em conta que sua formulação original remonta aos primórdios das sistematizações desse campo, tem a virtude de organizar as diferentes modalidades de ações segundo sua abrangência territorial e sociológica. Na segunda modalidade, a centralidade do indivíduo pouco deixa a desejar, em termos de método e de construção teórica, à criminologia positivista, ainda que despojada de algumas das categorias médicas que a orientavam.

Uma outra tipologia, bem mais recente, foi proposta por Tonry e Farrington (1995). Por ela, focadas na prevenção, teríamos quatro grandes famílias de abordagens: prevenção à evolução criminal (developmental prevention), prevenção comunitária (community prevention), prevenção situacional (situational prevention) e prevenção criminal (criminal justice prevention). Cada um desses campos opera com modelos varia- 
dos de análise de risco e de determinantes para a existência de maiores ou menores taxas de incidência criminal, segundo características territoriais, sociais, econômicas, trajetórias de vida, estilos de vida etc. Segundo Tilley (2005), ele próprio formulador de tipologia semelhante, as formas de definição são inúmeras, havendo mesmo quem seja capaz de listar onze tipos diferentes de prevenção. Por economia argumentativa e preferência pessoal relativamente arbitrária, fiquemos com as quatro modalidades de Tonry e Farrington, examinando brevemente cada uma delas.

A prevenção à evolução criminal é focada na identificação dos fatores de risco que fazem mais provável que indivíduos se envolvam recorrentemente em episódios criminais. Embora, em tese, os fatores de risco que interessam digam respeito tanto à incidência de perpetração quanto de vitimização, na prática, os trabalhos inscritos nesse campo específico buscam predominantemente identificar os fatores que levam ao cometimento repetido de ações violentas pelos indivíduos. Do ponto de vista sociológico, a verificação de determinadas regularidades possibilitaria distinguir quais seriam as causas para uma propensão maior ao cometimento de atos violentos por parte de certos indivíduos. Uma parcela destas estaria diretamente relacionada a traços de personalidade e propensões de humor. Inevitável lembrar, ainda que de passagem, o foco nas trajetórias individuais e no insulamento do indivíduo mencionados anteriormente.

Com uma ênfase, porém, incomparável àquela encontrada em qualquer texto de referência da criminologia positivista, os estudiosos inscritos nessa corrente vão buscar nos liames das histórias individuais e suas articulações com as instâncias básicas de socialização os principais fatores que concorrem para a propensão ao envolvimento em situações de violência. Embora não sejam totalmente ignorados, os fatores inatos à constituição física dos indivíduos estão longe de ocupar a atenção dos pesquisadores vinculados a essa 
corrente do modo como observamos entre os positivistas. Cabe repetir, contudo, que o indivíduo é unidade de análise central e que as instituições penais são a fonte privilegiada de dados, assim como ocorria entre os positivistas.

Estruturas familiares, carreiras escolares, perfil socioeconômico da vizinhança são alguns dos campos em que germinariam e seriam encontrados os fatores de risco. Além do interesse sociológico, a perspectiva de isolar o que é determinante daquilo que pode ser visto como incidental para a configuração das tendências criminais dos indivíduos é um importante input na definição de estratégias e políticas públicas voltadas para a redução dos fatores de risco vigentes em determinados setores do corpo social ${ }^{4}$.

Um dos desafios metodológicos dessa abordagem é verificar dentre as variáveis passíveis de serem levadas em conta quais são dependentes e quais incidem significativamente sobre a recorrência de envolvimento em situações 24 de violência. Sofisticados modelos analíticos têm sido postos a serviço de trabalhos dessa natureza e, a luz da produção disponível, é possível chegar a inferências relativamente seguras segundo recortes previamente estipulados. Estilos de vida específicos tendem a aumentar a vulnerabilidade de certos grupos sociais, como os jovens, por exemplo. Indivíduos com histórico familiar conturbado e sem a presença de um dos pais em seus primeiros anos de vida tendem a ser mais suscetíveis a comportamentos violentos do que aqueles cujo percurso foi pautado pela presença de pai e mãe. Entre os primeiros, aqueles que foram privados da presença materna tendem a ser mais suscetíveis do que aqueles privados da presença paterna. Tais inferências podem ser e são desenvolvidas segundo uma série de desdobramentos possíveis.

\footnotetext{
${ }^{4}$ Um bom apanhado de estudos inscritos nessa perspectiva pode ser encontrado em Farrington e Welsh (2006).
} 
Embora haja algumas pesquisas que dão suporte às definições dos fatores de risco, causa desconforto a constatação de que certos modelos moralmente aceitos e historicamente circunscritos às sociedades modernas acabam sendo reiterados empiricamente por pesquisas que em geral os próprios responsáveis reconhecem como precárias. São exatamente os casos, por exemplo, em que fatores de risco associados a trajetórias escolares, dificuldades de aprendizado ou estrutura familiar se destacam como variáveis explicativas para comportamentos desviantes. Do mesmo modo, a despeito dos cuidados e da sofisticação metodológicos, desconcerta a constatação de que os fatores de risco pesam exatamente sobre os segmentos sociais mais desfavorecidos e mais comumente identificados pelo que abordagens de antiga tradição costumam apontar como classes perigosas. Teríamos, assim, uma espécie de reiteração científica das intervenções mais comprometidas politicamente, seja dos setores mais conservadores, seja das correntes mais reformadoras do debate público. Uma meta-análise dessa perspectiva tende a gerar um certo desconforto quanto à possibilidade de que as perguntas feitas e o modo de formulá-las não resultam, como no final do século XIX, na confirmação de suspeitas estabelecida a priori e fundadas dotadas de enviesado conteúdo moral.

Para além do que já foi mencionado, há de se notar ainda o caráter não conclusivo de tais pesquisas e sua falsificação, igualmente precária e parcial, por alguns experimentos. Esse último caso é ilustrado por um conhecido estudo longitudinal realizado com 411 pessoas do sexo masculino nascidas em 1953 num bairro operário na Inglaterra (Tilley, 2009). A partir de uma definição de seis fatores de risco cuja incidência combinada indicaria maior tendência a uma carreira criminal $^{5}$, foram feitas algumas rodadas de

\footnotetext{
${ }^{5}$ Os fatores levados em conta foram: uso de drogas nos últimos doze meses quando os pesquisados tinham entre 12 e 17 anos; amigos ou parentes com histórico de agressão quando tinham entre 12 e 17 anos; uso regular de bebida alcoólica
} 
investigação sobre as trajetórias dos membros daquele universo, sendo a primeira realizada quando tinham entre 8 e 9 anos. Na última checagem, realizada por Farrington e colaboradores, em 2006, os resultados revelaram-se inconclusivos. Indivíduos que não figuraram como membros do grupo de risco tiveram uma carreira criminal, enquanto outros, que passaram por experiências que os condenariam a uma trajetória de crimes, escaparam desse círculo. Uma das explicações aventadas para o "fracasso" do experimento foi o reduzido número de variáveis utilizadas pelo estudo.

Os aspectos próprios da prevenção ao crescimento criminal destacados nos parágrafos anteriores fazem-na muito mais próxima da criminologia positivista do que poderíamos supor à primeira vista. O ponto de partida analítico dessa perspectiva é a verificação de altas incidências de episódios criminais em territórios e/ou envolvendo grupos específicos. Os traços particulares que, em tese, singularizam tais 26 recortes são dados a partir da convergência de premissas teóricas gerais e inferências empiricamente fundadas pela análise de dados recolhidos através dos recursos que já em Ferri são advogados como cruciais para a devida compreensão do fenômeno criminal. Se o processo que leva da construção de modelos à verificação de hipóteses explicativas se inverte (a tipologia, no caso positivista, é o resultado de exaustiva investigação sobre o perfil individual, enquanto este é definido, na presente modalidade de prevenção, como ponto de chegada de uma análise predominantemente sociológica), temos, como resultado final em ambos os casos, a construção de perfis individuais de perpetradores contumazes e continuados de ações criminosas.

Alcoolemia, drogadicção, aprendizado deficiente, família desestruturada, históricos de vitimização infantil são 
variáveis recorrentes na identificação dos fatores de risco tanto da prevenção à evolução criminal, quanto do positivismo criminológico, inclusive tal como formulado por Lombroso. As instituições sociais trazidas à cena pouco diferem daquelas que compõem o diagnóstico de crise do mundo europeu, tal como desenvolvido por Durkheim em parte substantiva de sua obra sociológica e reformista. A distância histórica e epistemológica não é motivo para a inibição do exercício de aproximação, sobretudo se temos em mente os desdobramentos discricionários e racistas de que foram objeto as teses positivistas, como forma de se evitar uma apropriação semelhante para o caso presente.

Por outro lado, num contexto de endurecimento penal e de recrudescimento das abordagens penalistas, tal como descrito por Garland (2002), entre outros, a perspectiva de prevenção apresentada aqui reaproxima, assim como já advogavam alguns positivistas, a abordagem prática da questão criminal de intervenções que, ao longo dos dois últimos séculos, acabaram circunscritas a um suposto campo especializado da assistência social. Acompanhamento familiar, experimentos de educação especial, programas de socialização são despidos de um cunho puramente humanitário, passando a ser reconhecidos como investimentos focados na produção de bens coletivos e de interesse comum. Se levado a sério, esse pode representar um passo importante para a atualização da abordagem do problema da segurança e sua ampliação no escopo de intervenções de agências do Estado ou de fora dele. Tal incorporação, note-se bem, implica uma redefinição na própria abordagem de possíveis iniciativas nessa linha, que deixam de estar estritamente identificadas à filantropia ou a políticas distributivas e passam a ser assumidas também abertamente (ainda que não de modo exclusivo) como mecanismos de controle social. Esse último ponto é fundamental. 
A julgar corretas as inferências extraídas das pesquisas e análises pertinentes a esse campo específico da prevenção, temos fortes indícios de que um dos problemas de fundo da segurança pública contemporânea seja a exaustão de mecanismos de controle que de certa forma se conformaram e se instituíram na modernidade. Se isso faz sentido, discutir criminalidade e as formas de lidar com tal problema equivaleria a abordar, a partir de uma determinada angulação, problemas que excedem esse campo específico e dizem respeito a mudanças significativas nas estruturas básicas de socialização, bem como sua eficácia em produzir padrões de ordenamento social.

Uma segunda perspectiva assumida contemporaneamente é a prevenção comunitária. Ela parte do pressuposto de que as condições sociais e institucionais de certas áreas concorrem para a degradação das relações sociais, fomentando, assim, os casos de violações da lei e de violências. 28 Uma das mais famosas teorias inscritas nessa perspectiva é a polêmica teoria das janelas quebradas, formulada por Kelling e Coles (1996). Segundo essa conhecida teoria, um ambiente descuidado, em que a violação de códigos elementares de conduta e de respeito ao patrimônio e ao espaço público são toleradas, acaba por ser o campo fértil para escaladas de violência e o incremento de tipos mais graves e com maiores potenciais de agressão. Na versão adotada pelo prefeito de Nova York, Rudolph Giulianni, a base dessa teoria se converteu na chamada política de tolerância zero que, minimizadas outras postulações e iniciativas, como fortalecimento dos laços societários, criação de atividades voltadas para o desenvolvimento de valores positivos e programas sociais para jovens e para famílias, em geral, foi exportada para várias as partes do mundo. Outros estudiosos importantes formularam análises de uma perspectiva próxima, com maior ênfase no investimento social e recuperação de áreas degradadas. 
Wesley Skogan (1990), por exemplo, reúne dados de quarenta comunidades situadas em innercities de várias cidades norte-americanas com o intuito de analisar as dinâmicas em que a degradação do espaço público está associada a altas taxas de desordem social. Embora não estabeleça uma conexão direta entre desordem e crime a partir de seus dados empíricos, Skogam admite a consistência de, especulativamente, relacioná-las, remetendo os comportamentos inscritos em uma ou outra categoria como vetores importantes e decorrência da desagregação de laços de pertencimento e solidariedade. Para esse tipo de abordagem, duas modalidades de intervenção têm sido levadas a termo: o policiamento de aproximação, pelo qual as forças policiais identificam os fatores que mais acentuam a degradação dos laços comunitários, e o incentivo à criação de redes de cooperação e ajuda mútua para a erradicação dos focos de perturbação da ordem e produção de episódios criminais.

Embora nesse caso a definição de perfis individuais não tenha a centralidade verificada no caso anterior, temos também aqui a ressonância de teses clássicas e positivistas sobre o crime. Em primeiro lugar, para além de fatores naturais ou clínicos - objetos privilegiados dos positivistas -, observamos a assunção aberta de que, o ambiente, o entorno social, é um fator fortemente relacionado aos níveis de incidência criminal. Em segundo lugar, o postulado segundo o qual o entorno refere-se à ambiência física tanto quanto às redes sociais, confere um aporte teórico que amplia os horizontes teóricos da prevenção comunitária a campos diversos dos debates sociológicos. Comunidades dotadas de laços relativamente sólidos de pertencimento, imbuídas de valores públicos razoavelmente cultivados, dotadas de iniciativa, composta por indivíduos animados por uma espécie de interesse bem-compreendido (a remissão à Toqueville é mais do que pertinente aqui), tendem a reproduzir e consolidar virtudes 
públicas que mitigam o desvio e o comportamento criminal. Indivíduos despojados desses traços habitam regiões sombrias e degradadas, reproduzindo e perpetuando sua própria indigência.

Investir no espaço físico e simbólico onde as incidências criminais são frequentes é uma um desdobramento prático quase inevitável de uma abordagem como essa. Embora também nesse caso haja riscos discriminatórios embutidos em seus possíveis desdobramentos, sua baixa efetividade, segundo pesquisas disponíveis, acaba sendo um dado mais preocupante e digno de nota. Segundo os dados analisados por Skogan (1990), anteriormente citado, as iniciativas "civilizadoras" utilizadas tendem a produzir alguns resultados em áreas não degradadas e têm impacto quase nulo exatamente onde se verificam os vetores criminais destacados. Ou seja, do ponto de vista de sua efetividade, a prevenção comunitária é, hoje, uma tese a ser comprovada 30 no que toca à redução da criminalidade. Seus resultados parecem muito próximos ao dos estudos sobre cultura cívica de Almond e Verba (1963) a Puttnan (1993), nos quais há uma circularidade argumentativa em que a existência de uma cultura cívica implica a existência de indivíduos ativos e imbuídos de espírito público e o vigor da cultura cívica é condição para a existência de indivíduos ativos e imbuídos de espírito público.

De todo modo, também pesa em favor dessa perspectiva a ampliação da abordagem da questão do crime e a elaboração de instrumentos não estritamente punitivos para lidar com ele. Apenas para sublinhar, deve-se ter em mente que ambas as "virtudes" também se desenhavam nas principais formulações positivistas, ainda que a partir de um repertório mais reduzido e, à luz do conhecimento histórico adquirido posteriormente, discutível.

A prevenção situacional é uma abordagem ancorada estritamente na ontologia utilitarista. Seguindo tal perspec- 
tiva, a ação do violador da lei é orientada segundo os mesmos padrões verificáveis na conduta dos indivíduos tomados em geral: suas escolhas são pautadas pelo cálculo custo/ benefício tendo em vista os resultados que pretende obter. Dessa transposição da racionalidade econômica para a conduta criminosa, temos que, para os defensores da prevenção situacional, a incidência de ações criminosas tenderá a ter uma relação direta com as oportunidades de estas resultarem em maiores ganhos efetivos para seus perpetradores e, por outro lado, será inversamente proporcional aos custos possíveis de serem arcados pelos mesmos. Nessa linha, a prevenção implica fundamentalmente intervir nos espaços onde há incidências de determinados tipos de delitos de modo a tornar seu cometimento menos atraente, aumentando os riscos palpáveis de fracasso e de aplicação de sanção sobre seus perpetradores. Em uma palavra, a prevenção situacional confere subsídios normativos e empíricos para a criação de espaços defensivos, recursos tecnológicos, mecanismos de dissuasão etc.

Embora seja encarada como uma perspectiva de desenvolvimento recente, alguns de seus defensores indicam que tal abordagem esteve no horizonte da criminologia desde o século XIX, sendo relegada a segundo plano devido à primazia das explicações criminológicas que se concentraram nos aspectos individuais do comportamento criminoso. De fato, a perspectiva situacional desloca o foco do criminoso para o ambiente em que o crime é ocorre. Mas tal deslocamento se dá não exatamente por que o indivíduo seja desprovido de importância. Ao contrário, ele é a fonte única de decisões orientadas por escolhas racionalmente orientadas. O lugar de coadjuvante ocupado pelo indivíduo na teoria situacional decorre de seu caráter não problemático. Aqui, o homem criminoso é, na maior parte das vezes, um indivíduo comum, dotado das aptidões medianas de que dispõe qualquer cidadão e motivado pelo principal recurso 
de que são investidos os homens e mulheres em geral: a utilidade. Por isso, de certa forma, a prevenção situacional é a menos sociológica das perspectivas aqui apresentadas. Por outro lado, ao menos do ponto de vista teórico não deixa de ser instigante a tendência a destituir o agente de condutas criminais de traços aberrantes ou patológicos.

De maneira resumida, segundo essa linha, o ambiente favorável a obtenção de ganhos com baixos custos ou custo zero mediante ações criminosas funcionaria como um estímulo para que indivíduos racionais fizessem suas escolhas. Esses mesmos indivíduos, constrangidos pela projeção negativa do resultado de seus cálculos, abdicariam da ação em função da perspectiva hostil a possibilidade de ganhos. $\mathrm{O}$ corolário prático desses postulados é a delimitação de determinadas áreas de incidência de certos tipos de delitos e a intervenção sobre as mesmas de forma a reduzir ou suprimir seus atrativos. Em consonância com a ontologia que a 32 fundamenta, a perspectiva situacional tem se desenvolvido e, aparentemente, obtido resultados promissores no que diz respeito a crimes contra o patrimônio. Por ser de encampação recente, os experimentos pautados por ela costumam ser abordados de forma prudente mesmo por seus defensores, e as análises e avaliações de impacto tendem a ser encaradas como estudos de caso que se vão acumulando lenta, mas solidamente ao longo dos anos ${ }^{6}$.

A ideia de render-se ao reducionismo economicista não chega a ser muito alentadora, mas se concedendo algum rendimento aos postulados situacionais, poder-se-ia imaginar uma reorientação de seu foco, ampliando a noção de ganho para além dos estreitos limites do mundo material. A julgar que a expectativa de obter ganhos de natureza diversa pode ser motivação para o cometimento

\footnotetext{
${ }^{6}$ Para alguns dos experimentos nessa perspectiva, ver estudos reunidos por Clarke (1997).
} 
de ações criminosas e para o envolvimento em dinâmicas violentas, poderíamos imaginar um conjunto de valores e estratégias adaptativas que levam certos sujeitos a essas escolhas independentemente de ganhos materiais propriamente ditos. O desdobramento mais imediato dessa ampliação, contudo, seria recolocar o sujeito no cerne do enredo, deslocando o foco do ambiente e, com isso, abdicar do traço que singulariza a prevenção situacional em relação a outras abordagens criminológicas. Sendo assim, é difícil, ao menos hoje, ampliar tal perspectiva, mantendo-se seus fundamentos e axiomas básicos, para além dos limites de certas modalidades muito específicas de crime.

No plano prático, algumas das medidas possíveis e efetivas inscritas na prevenção situacional não estão a salvo de reparos e críticas de natureza moral. O repertório de intervenções da prevenção situacional é numeroso e variado: recursos tecnológicos de ponta, como sistema de monitoramento por câmeras, sujeito a críticas pelo potencial invasivo que tem embutido no que toca às liberdades individuais; intervenções no desenho urbanístico de certas áreas, muitas vezes comprometendo a possibilidade de ocupação pública das mesmas; uso ostensivo de segurança privada, que reforça a sensação de vigilância; criação de mecanismos variados de controle de frequência de certos personagens identificados como potencialmente hostis em determinados espaços, como os centros comerciais, medida cujo caráter segregacionista é reconhecido até mesmo por seus defensores, estão entre os muitos recursos que podem ser entendidos como intervenções no espaço e nas formas de sua ocupação próprias da ação situacional. A questão de saber sobre os custos que se está disposto a arcar em favor de maior segurança, tem sido recorrentemente colocada de forma especialmente enfática, quando tratamos dessa modalidade de prevenção.

"Prevenção criminal" é o nome genérico dado a um conjunto razoavelmente amplo de estratégias que têm 
como protagonistas algumas das instituições que compõem o sistema de justiça criminal. Elas são, ou podem ser, muitas e têm em comum o lugar onde estão radicadas: o aparelho estatal. O conjunto mais conhecido, acionado e, de certo modo, estudado é aquele inscrito nas instituições de execuções penais. Como é sabido, ao menos em tese a prevenção faz parte do escopo do sistema de execução penal, orientando-se pela expectativa de redução da incidência através de mecanismos ressocializadores e dissuasivos. Como já anotamos, a expectativa preventiva é contemplada, ainda que com reservas, no desenho do sistema punitivo mesmo em Lombroso. Na verdade, ela remonta a Beccaria e isso se nos ativermos somente aos primórdios das formulações modernas sobre o sistema punitivo. Do mesmo modo, as instituições policiais, tal como as conhecemos a partir do século XIX e em sua faceta ostensiva, têm como fundo a evitação de tumultos e episódios violentos.

34 Ainda que não concedamos um sentido tão amplo à noção de prevenção, circunscrevendo-a a uma forma de lidar com o fenômeno criminal orientada por preceitos mais solidamente voltados para a antecipação, as agências do sistema de justiça criminal ocupam um lugar importante, tendo, por seus respectivos mandatos e especializações, um potencial bastante significativo. Nessa vertente, encontram-se, por exemplo, os recursos utilizados para lidar com o controle de certos fatores de risco como o acesso a armas, as formas de tornar as instâncias de mediação de conflitos acessíveis a populações marginalizadas, os instrumentos de regulação e sanção de hábitos que aumentam a vulnerabilidade ou os comportamentos agressivos e os meios de identificação de focos potenciais de produção ou reprodução de condutas violentas.

Dada a impossibilidade de descrever cada uma das abordagens inscritas nessa família tão ampla, e tendo em vista as inúmeras controvérsias acerca da efetividade e das implica- 
ções éticas e econômicas de cada uma, citemos, de forma sumária, duas, que simultaneamente se inscrevem nesse campo e mobilizam saberes e orientações bastante específicas. Ambas dizem respeito ao trabalho policial entendido de forma genérica: os programas de controle de armas e as várias modalidades de policiamento de aproximação.

Levados a cabo em diversas cidades norte-americanas e europeias, os programas de controle de armas partem do diagnóstico empiricamente comprovado de que o potencial letal de conflitos e episódios envolvendo violência cresce significativamente em virtude da presença de armas de fogo. A posse e o porte de armas, contudo, têm a ver com marcos jurídicos e culturais. Sua comercialização envolve agentes e interesses variados e poderosos. Frequentemente, as armas que circulam nas ruas das grandes cidades, que se encontram de posse de gangues, de grupos ligados ao tráfico de drogas, de criminosos comuns e avulsos têm origem legal, foram postas no mercado segundo os preceitos que o regulam e geraram empregos e impostos. Ostentá-las confere autoridade e respeito a seus proprietários e, mesmo em mãos de cidadãos comuns, normalmente são identificadas como recurso de segurança. Destrinçar os percursos tortuosos que levam da legalidade à ilegalidade implica investimento de altas somas e um paciente trabalho de inteligência. Desfazer as redes de significação que conferem positividade a um devastador fator de risco implica dissuasão e convencimento. Embora a segunda estratégia esteja longe de resumir-se às vocações policiais (a rigor, têm pouco a ver com elas), a primeira necessariamente envolve um corpo especializado e autorizado a aplicação de medidas de controle e punição exclusivas de uma polícia ultraespecializada em investigação e inteligência. As alegações em defesa da efetividade do controle de armas sobre o crime (o crime letal, sobretudo) não são sempre e invariavelmente convincentes (há pouco de conclusivo em se tratando de 
prevenção), mas as apostas têm sido pesadas nesse campo, incluindo aí altos investimentos em recursos públicos. De todo modo, cabe salientar que o sucesso das iniciativas nesse campo tende a se concentrar em medidas estatais e repressivas, com as campanhas e propagandas educativas ocupando um lugar subsidiário.

Outra modalidade preventiva envolvendo agentes policiais, que implica uma expertise radicalmente diversa da anterior, é aquela sob cuja rubrica se inscrevem os programas de aproximação polícia e comunidade. Policiamento comunitário, policiamento orientado para a solução de problemas e policiamento voltado para a resolução de conflitos são algumas dessas modalidades. Deixando de lado as especificidades e sutilezas que os diferenciam entre si, é possível tratá-las conjuntamente enfatizando os traços gerais que as pautam. Todas elas supõem um estreitamento de contato entre os agentes policiais e a população do espaço em que 36 atuam. Tal aproximação, supõe-se, cria laços de cooperação de forma que, sem prejuízo de sua autoridade, o policial identifica a comunidade como beneficiária primeira de seu trabalho. Esta, por sua vez, vê no policial um servidor público investido de prerrogativas que implicam o uso da força, mas cujo trabalho é devotado primordialmente para o provimento de segurança e ordenação social.

As ênfases justificadoras dessa modalidade de policiamento variam, mas todas estão pautadas pela lógica da aproximação e da antecipação. O trabalho de Herman Goldstein (1990) é consensualmente apontado como pioneiro do modelo de policiamento orientado para a solução de problemas. Nele, a aproximação é tratada como mecanismo eficaz de otimização do trabalho policial, criando condições para a efetuação de prisões, desarticulação de gangues e quadrilhas, redução de incidências de roubo, uso e comércio de drogas e outras práticas ilegais envolvendo violência. Deve-se ter em mente que a perspectiva desenhada por 
Goldstein está focada na melhoria da qualidade e da eficácia do trabalho policial e seu caráter proativo tem essa meta. De suas formulações, surgiram várias iniciativas inovadoras de gerenciamento do trabalho de polícia e um sem número de discussões acerca de sua natureza e efetividade.

Com objetivos e estratégias semelhantes, mas enfatizando aspectos mais "brandos" das atividades de rotina do trabalho policial, o policiamento comunitário espera obter resultados sobre a criminalidade mediante a criação de laços de confiança e cooperação com as comunidades. Tal proximidade implicaria uma espécie de "humanização" do profissional de polícia, porta de entrada para a criação de mecanismos de ausculta e, consequentemente, de diagnóstico de focos potenciais de violência e crime. O mesmo vale para o modelo de policiamento de aproximação.

Alguns dos limites da eficácia desses modelos de policiamento são semelhantes àqueles observados na prevenção comunitária. As pesquisas apontam que estratégias de aproximação e de criação de laços de confiança polícia/comunidade tendem a ser expressivas em áreas de baixas incidências criminais violentas, perfil socioeconômico mais elevado e maior associativismo. Áreas conflagradas, que concentram minorias étnicas e apresentam altas taxas de criminalidade violenta, tendem a ser refratárias a tais estratégias e a desconfiança, assim como a hostilidade recíproca, costuma prevalecer. Tais avaliações, contudo, não são conclusivas.

De certo modo, pode-se dizer que a ênfase na prevenção através das instâncias do sistema de justiça criminal tendo o aparato policial como protagonista, encontra suas raízes nas teorias do Estado moderno, formuladas com maior sofisticação a partir do século XIX. Talvez surpreenda a constatação de que este é um postulado desenvolvido por Hegel (1997), nas segunda e terceira seções da terceira parte de Princípios da filosofia do direito. Ali, ainda que de forma pouca desenvolvida, estão destacados dois imperativos na pas- 
sagem da sociedade civil para o Estado: 1. A constituição de uma força policial que difira das forças armadas com a atribuição de garantir a coesão social e o respeito às leis do Estado no âmbito estritamente doméstico; 2. O mandato de que essa força está investida: prevenir possíveis desvios que ponham em questão tal ordenamento e levem a sociedade ao risco do colapso.

É óbvio que o foco nas agências estatais como instâncias privilegiadas de intervenção proativa não equivale necessariamente a se negligenciar instâncias da sociedade ou da iniciativa privada como atores relevantes. Por outro lado, tal ênfase pode implicar um enfraquecimento excessivo dos processos de construção de estratégias e uma certa autonomização dos agentes autorizados a agir em relação àqueles que, em tese, deveriam se beneficiar dos mecanismos produtores de ordenamento e evitação do crime. Sendo esse o caso, temos um quadro que se afasta dos postulados mais 38 avançados do positivismo, criando as condições para o engendramento de uma lógica pautada predominantemente pelo uso da força e de recursos punitivos como mecanismos de dissuasão e controle.

$$
* * *
$$

As distâncias teóricas, metodológicas e epistemológicas entre a criminologia positivista e as criminologias sociológicas são conhecidas e já foram exaustivamente apontadas. Fazer o movimento oposto, colocando-as em diálogo e localizando proximidades não equivale a esquecer o que as separa. Pode, outrossim, representar um exercício salutar de crítica e alerta quanto a procedimentos analíticos presentemente praticados. Haja vista o caráter supostamente recente dessas abordagens focadas na prevenção do crime, bem como sua pretensão antecipatória e sua clara ambição de, através de recursos e inferências cientificamente fundadas, interferir 
nas dinâmicas sociais com instrumentos e fins defensáveis também do ponto de vista normativo, fazer tal operação a partir destas torna esse exercício ainda mais interessante.

Posto o diálogo, os teóricos contemporâneos da prevenção talvez tenham muito mais do que supõem a aprender com alguns positivistas, não propriamente para copiar-lhes métodos, convicções ou princípios teóricos, mas sobre eventuais desdobramentos inesperados de suas teses. $\mathrm{O}$ foco no indivíduo, as formas de criar categorias que inadvertidamente se tornam reiterativas de valores morais consagrados e as apostas, por vezes perigosamente ingênuas, em distinções como eficiência e ineficácia, mecanismos brandos e duros de controle parecem reduzir as aparentemente abissais distâncias entre a criminologia praticada no século XIX e aquela que vige atualmente. Não deixa de ser irônico surpreender em espíritos tão sinceramente comprometidos com o saber científico e com preceitos humanitários, como o eram Lombroso e Ferri, por exemplo, a formulação de teses tão propícias ao racismo, à discriminações culturais e regionais de toda sorte. Isso pode ser visto claramente hoje, em função do distanciamento histórico, benefício de que não dispomos para análises reflexivas da prevenção criminal contemporânea. Colocar o passado em diálogo com o presente, em lugar de tratá-lo como algo sepultado pelo avanço científico e superado pelo amadurecimento de um campo disciplinar, pode informar melhor sobre o que é feito nos tempos atuais.

\section{João Trajano Sento-Sé}

é professor de Ciência Política da UERJ e coordenador do Laboratório de Análise da Violência da mesma instituição.

\section{Referências bibliográficas}

ALMOND, G.; VERBA, S. 1963. The civic culture: political and democracy in five nations. Newburry Park: Sage Publications. 
BECCARIA, C. 2005. Dos delitos e das penas. São Paulo: Martins Fontes.

CLARKE, R. V. 1997. Situational crime prevention: successful case studies. Monsey: Criminal Justice Press.

FARRINGTON, D. \& WELSH, B. 2006. Preventing crime: what works for children, offenders, victims and places. Nova York: Springer.

FERRI, E. 2009. Criminal sociology. Valde Books (versão Kindle).

GARLAND, D. 2002. "Ideas, institutions and situational crime prevention". In: VON HIRSCH, A.; GARLAND, D.; WAKEFIELD, A. Ethical and social perspectives on situational crime prevention. Oxford: Hart Publishing.

GOLDSTEIN, H. 1990. Problem-oriented policing. Nova York: McGraw Hill.

HAYEK, F. A. 1978. New studies in philosophy, economics and the history of ideas. Londres: Routledge.

HEGEL, F. 1997. Principes de la philosophie du droit. Paris: Gallimard.

KELLING, G.; COLLES, C. 1996. Fixing broken windows: restoring order and reduction crime in our community. Nova York: New York Free Press.

LOMBROSO, C. 2006. The criminal man. Durham/Londres: Duke University Press.

SKOGAN, W. G. 1990. Disorder and decline: crime and the spiral of decay in American neighborhoods. Berkeley/Los Angeles: University of California Press.

40 TILLEY, N. 2005. "Introduction: thinking realistically about crime prevention". In: (org.). Handbook of crime prevention and community safety. Portland: Willan Publishing. . 2009. Crime prevention. Devon: Willian Publishing.

TONRY, M.; FARRINGTON, D. 1995. "Strategic approaches to crime prevention". In: (orgs.). Building a safer society: strategic approaches to crime prevention. Chicago: University of Chicago Press. 


\section{PREVENÇÃO AO CRIME E TEORIA SOCIAL}

JOÃO TRAJANO SENTO-SÉ

$\mathrm{O}$ artigo estabelece um diálogo entre a criminologia positivista e algumas correntes contemporâneas da prevenção ao crime inspiradas em teorias sociológicas. Através desse exercício, busca-se evidenciar que algumas das formulações focadas no campo da prevenção já aparecem, em estado embrionário, na agenda teórica positivista. Do mesmo modo, torna-se possível explicitar que alguns postulados empíricos e práticos do positivismo são menos estranhos às teorias contemporâneas de prevenção ao crime do que se costuma reconhecer.

Palavras-chave: Criminologia; teorias de prevenção da violência; teoria social

\section{CRIME PREVENTION AND SOCIAL THEORY}

The article establishes a dialogue between positivist criminology and some contemporary currents on crime prevention inspired in sociological theories. Through this exercise, we seek to highlight that some of the formulations focused in the preventions field appear, in embryonic state, in the positivist theoretical agenda. Likewise, it is possible to explicit that some empirical and practical tenets of positivism are less foreign to contemporary theories of crime prevention than is usually recognized.

Keywords: Criminology; violence prevention theories; social theory 